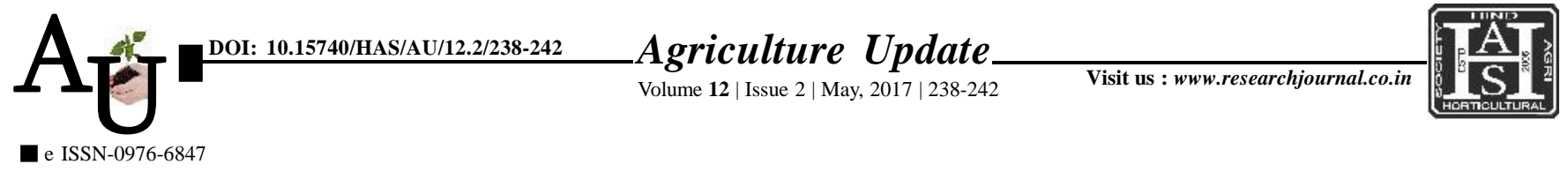

\title{
Research Article: Perception of Sathgudi orange growers on contract farming
}

GINOD ANAVRAT AND MAMTA MOKDE

Article Chronicle:

Received :

23.02.2017;

Revised :

16.03.2017;

Accepted :

30.03.2017

KeY Words :

Sathgudi orange,

Contract farming,

Perception
SUMMARY : The present study was carried out during 2015-16 in the Nalgonda and Anantpur districts of Telangana and Andhra Pradesh, respectively. It aimed at ascertaining the Sathgudi orange growers' perception towards contract farming and find out the issues governing profitability. The total sample of 100 was derived from four talukas in the two districts using simple random sampling. The data collected through a structured interview schedule were analyzed using the t-test of significance of difference between sample and population means. The study revealed that education, social participation and communication behaviour showed non-significant relationship whereas occupation $(\mathrm{t}=-0.962)$, land holding $(\mathrm{t}=-0.484)$ and per hectare productivity $(\mathrm{t}=-1.901)$ showed negative relationship. It implies that, the Sathgudi orange growers are averse to the concept of contract farming. However, access to improved/appropriate technology was perceived as the main prospective reason which appealed to the maximum respondents $(\mathrm{RBQ}=69.75)$. It discerns that, for want of appropriate technology they are incurring monitory loss which otherwise would have been minimized. Lack of or inadequate cold storage facilities in the market premises $(\mathrm{RBQ}=98)$ has been rated as the issue of prime concern that govern profitability.

How to cite this article : Anavrat, Vinod and Mokde, Mamta (2017). Perception of Sathgudi orange growers on contract farming. Agric. Update, 12(2): 238-242; DOI : 10.15740/HAS/AU/12.2/238-242.
Author for correspondence :

VINOD ANAVRAT ICAR-Central Citrus Research Institute, NAGPUR (M.S.) INDIA Email:vinodanavrat@ gmail.com

See end of the article for authors' affiliations 